\title{
Economic Burden and Impact on Quality of Life of Herpes Zoster in Spanish Adults Aged 50 Years or Older: A Prospective Cohort Study
}

\author{
Javier Díez-Domingo (D) - Desmond Curran (D) - Maria del Rosario Cambronero (D) • \\ Juan-Antonio Garcia-Martinez (D) · Sean Matthews (iD
}

Received: December 22, 2020 / Accepted: March 18, 2021 / Published online: May 19, 2021

(c) GlaxoSmithKline Biologicals S.A. 2021

\begin{abstract}
Introduction: The economic burden of herpes zoster (HZ), including its most common complication, postherpetic neuralgia (PHN), and its impact on health-related quality of life (HRQL) is not well described in Spain. The aim of this study was to estimate HZ-related healthcare costs and impact on HRQL in Spanish adults aged 50 years or older.

Methods: A prospective, observational study was performed with patients with HZ recruited through four general practitioner networks in Spain (NCT01521286). HRQL data were collected using the EuroQoL-5 Dimension (EQ-5D) questionnaire; HZ-related pain and associated
\end{abstract}

Supplementary Information The online version contains supplementary material available at https:// doi.org/10.1007/s12325-021-01717-7.

J. Díez-Domingo

Vaccine Research Department, FISABIO-Public

Health, Valencia, Spain

D. Curran · S. Matthews

Value Evidence Department, GSK, Wavre, Belgium

Maria del Rosario Cambronero $(\bowtie)$.

J.-A. Garcia-Martinez

Medical Department, GSK, Technology Park of

Madrid, C/Severo Ochoa, no 2, 28760 - Tres Cantos,

Madrid, Spain

e-mail: charo.m.cambronero-martinez@gsk.com interference with activities of daily living (ADL) were assessed using the Zoster Brief Pain Inventory (ZBPI) questionnaire at days 0 (HZ rash onset), 15, 30, 60, and 90; patients with PHN were assessed up until day 270. Medical resource utilization was recorded throughout study follow-up. Work loss for patients/caregivers was also assessed. Costs were calculated from both the payer and societal perspectives.

Results: A total of 545 patients with $\mathrm{Hz}$ were included, of whom 25 developed PHN. During days $0-30$ post $\mathrm{HZ}$ diagnosis, the mean EQ-5D utility score was 0.738 , equating to a utility loss of 0.138. Sleep was the ADL most affected component. The mean costs for $\mathrm{HZ}$ in the overall cohort were $€ 240$ and $€ 296$ from the payer/societal perspective, respectively; $€ 187 /$ $€ 242$ for patients with HZ without any HZ-related complications; and $€ 571 / € 712$ for patients who developed PHN. The majority of costs were incurred during days 0-30.

Conclusions: In Spain, HZ and HZ-related complications such as PHN reduce patient HRQL and increase the economic burden for both payers and society in general.

Trail Registration: ClinicalTrials.gov identifier NCT01521286.

Keywords: Economic burden; Herpes zoster; Impact; Postherpetic neuralgia; QALY; Quality of life 


\section{Key Summary Points}

Why carry out this study?

Herpes zoster is a disease caused by the reactivation of the chickenpox virus. Approximately $30 \%$ of adults will develop herpes zoster in their lifetime.

Significant pain which may last for months-postherpetic neuralgia (PHN) is an important complication.

Spanish data on the impact of herpes zoster and PHN is mainly from retrospective studies. We conducted a prospective study to evaluate the impact on the quality of life of patients at least 50 years of age and costs related to $\mathrm{HZ}$ and complications.

What was learned from the study?

Herpes zoster and PHN have a substantial economic burden and impact on the quality of life of adults at least 50 years of age in Spain.

The data from this study can help inform cost-effectiveness estimations of the benefit of vaccination strategies against herpes zoster.

\section{DIGITAL FEATURES}

This article is published with digital features, including a summary slide, to facilitate understanding of the article. To view digital features for this article go to https://doi.org/10.6084/ m9.figshare.14229665.

\section{INTRODUCTION}

Herpes zoster (HZ) is caused by the reactivation of varicella-zoster virus which remains latent in sensory ganglia after a previous varicella infection. HZ typically manifests as a unilateral, painful, vesicular rash limited to the affected dermatome [1]. For most patients, HZ resolves within 1 month of rash onset. The most common complication of HZ is postherpetic neuralgia $(\mathrm{PHN})$, clinically significant pain persisting or appearing 3 months after rash onset [2]. Pain during the acute $\mathrm{HZ}$ episode or PHN may have a substantial negative impact on patients' health-related quality of life (HRQL) and their physical/social activities [3-9]. The economic costs of HZ can be substantial [10].

$\mathrm{HZ}$ is relatively common, and incidence rates increase with increasing age [11], rising from 3.4 cases per 1000 patient-years (PY) in the overall population to $7-8 / 1000$ PY in those aged 50 years or older, and 10/1000 PY in those at least 80 years of age [12]. Recent prospective studies in Italy and Germany have reported incidence rates of 6.5/1000 PY and 6.7/1000 PY respectively in persons aged 50 years or older $[13,14]$. In most European populations, incidence is higher in women and far higher greater in the immunocompromised [15]. The proportion of those patients with $\mathrm{HZ}$ who develop PHN in recent studies from Italy, Germany, and the UK ranges between $10 \%$ and $12 \%$ [13-15]. Data from Spain is similar; large retrospective studies have reported incidence rates of 5.0/ 1000 PY in adults aged 18 years or older [16], and 7.2/1000 PY in those aged 50 years or older [17]. Similar to other countries, higher incidence is reported in women and in the immunocompromised, and in patients with specific comorbidities such as COPD [16-18]. PHN is estimated to develop in between $12 \%$ and $16 \%$ of patients $[19,20]$.

In Spain, data on the impact of $\mathrm{HZ}$ and complications such as PHN on HRQL and healthcare costs are limited, and studies are mainly retrospective in approach [16, 20-23]. As such additional data are of value to provide a better understanding of the impact of these aspects in Spain. Here we report results from a prospective study that evaluates the impact of HZ and PHN on patients' HRQL, healthcare resource utilization, and associated economic costs. 


\section{METHODS}

This was a prospective observational cohort study of patients presenting in primary care conducted between March 2012 and May 2015 (ClinicalTrials.gov Identifier NCT01521286). The final study report was completed in July 2017. Participating physicians were community physicians/general practitioners (GPs) belonging to one of four GP networks situated in the Madrid, Catalonia, and Valencia regions covering an estimated 96,300-person cohort aged 50 years or older.

Eligible participants were adults aged 50 years or older presenting in their GP's practice with acute HZ, defined as new unilateral pain (broadly defined to include allodynia and pruritus) accompanied by unilateral rash and no alternative diagnosis. Patients attending a secondary GP consultation within 7 days following a $\mathrm{HZ}$ diagnosis in another setting (e.g., emergency room/urgent care center) were also eligible. Subjects meeting these criteria were assessed by participating GPs on the basis of their ability to complete several study questionnaires and, if considered suitable, were enrolled after providing written informed consent.

\section{Data Collection and Patient Follow-Up}

For all patients, a case report form with demographic data, medical history, and clinical HZ information was completed by the GP during the initial visit, along with information obtained from any referring healthcare personnel providing care related to the $\mathrm{HZ}$ episode. Data for subsequent study time points were collected via study questionnaires or recorded by GPs on subsequent visits. Healthcare resource utilization data were also entered into case report forms at the initial visit. Patients were asked to record details of all subsequent healthcare resource utilization throughout the study.

All patients were to be followed up until assessment on day 90 after the initial visit, which corresponded to the first time the patient presented at the study site (and does not necessarily correspond to the date of $\mathrm{HZ}$ rash onset; day 0) (see Supplementary information and Table $S 1$ in the electronic supplementary material for details).

Data on the severity of $\mathrm{HZ}$ pain and impact upon activities of daily living (ADL) and HRQL were collected through questionnaires as reported in similar previous studies in patients with $\mathrm{HZ}$ from international studies and in those conducted in Germany, Italy, and Japan [24-27] which used the validated Zoster Brief Pain Inventory (ZBPI) and the EuroQoL-5 Dimension (EQ-5D) questionnaires [4, 7, 28, 29]. For assessment of subsequent pain, clinically relevant PHN was defined as the presence of HZassociated moderate or severe "worst pain" score $\geq 3$ on the ZBPI scale index persisting or appearing more than 90 days after onset of the rash [25-27, 30].

Patients completed both questionnaires at the initial visit/day 0 and at assigned days; all patients were followed up until day 90 , with questionnaires administered at days 15, 30, 60, and 90 . For the ZBPI questionnaire, reminders were sent to patients to prompt completion at relevant time points and return to the study centers (by mail/in person) until the end of follow-up. For HRQL, follow-up assessment using EQ-5D was carried out via telephone interview conducted by trained research personnel using scripted questions replicating the survey text [31, 32]. Patients without PHN completed the study at day 90. Patients with PHN were followed up till day 180 and those with PHN at day 180 were followed up until day 270.

\section{Pain and HRQL Assessments}

HZ-related pain was assessed using item 3 of the ZBPI questionnaire which asks patients to rate the "worst", "least", and "average" pain experienced over the previous $24 \mathrm{~h}$. HZ impact on ADL was also recorded using the ZBPI questionnaire as previously described $[25,26]$ (Supplementary information). The EQ-5D questionnaire was used to measure HRQL utility. A single summary weighted health utility index value was calculated using country- 
specific published preference weights (time trade-off, TTO) values as previously described [26]. Spanish TTO EQ-5D value sets were used to generate the utility score [33]; using these weights, the "worst imaginable health state" has a utility index of -0.654 , while 1.000 represents the "best imaginable health state".

\section{Healthcare Resource Utilization and Medical Costs}

Reported costs are as incurred in real time between March 2012 and May 2015. Unit costs for resources were taken from official sources as reported for 2014 [34] (Table S2 in the electronic supplementary material). Medication costs (inclusive of applicable taxes) were based on prices published by the Official General Council of the College of Pharmacists of Spain [35]. No cost updating was performed.

Costs were estimated from both a healthcare system (HCS) perspective, which assessed direct medical costs, and from the societal perspective, which included both direct medical costs and indirect costs incurred by the patient (or their caregiver). Direct medical costs included all GP and specialist medical visits, hospital admissions and outpatient visits, and costs of medical procedures, investigations, and medications. As the study was conducted within a primary care setting, some hospitalizations and all specialist visits were only reported as referrals. As such no details of length of hospital stay were recorded, and a mean length of stay of 9 days was assumed; this could be considered a conservative estimate, as previous Spanish data has reported an average length of hospitalization for $\mathrm{HZ}$ of 12.9 days [36]. The daily cost of inpatient hospital stay was $€ 325$ [34] (Table S2 in the electronic supplementary material). Indirect costs included all expenditures incurred by patients, including productivity losses due to lost working days (for those patients in active employment), and out-of-pocket expenses (including any medical co-payments); productivity loss by caregivers were also included (Supplementary information).

\section{Data Analysis}

Descriptive statistics (mean values, standard deviation [SD] or standard error [SEs] and percentages) are presented for patient demographics, ZBPI pain severity scores, and for healthcare resource utilization outcomes and costs. Data were analyzed for the overall study cohort (all patients with HZ), by age strata, and also categorized on the basis of complications, with minor differences in categorization used in the HRQL and economic analyses (see the appendix in the electronic supplementary material). All analyses were carried out using SAS software version 9.2.

\section{Compliance with Ethics Guidelines}

This study was conducted in accordance with the ethical principles originating in the Declaration of Helsinki, the principles of Good Clinical Practice, and all applicable regulatory requirements. Written informed consent was obtained from each enrolled participant prior to any study data collection. The study protocol, the informed consent form, and other information that required pre-approval were reviewed and approved by the investigational center independent ethics committee (IEC) or institutional review board (IRB) for each of the participating primary care networks. These committees were the following: Comité Ético de Investigación Clínica Corporativo de Atención Primaria de la Comunitat Valenciana, Comité Ético de Investigación Clínica de la FUNDACIÓ UNIO CATALANA HOSPITALS, and Comité Ético de Investigación Clínica del Hospital Universitario Ramón y Cajal. The study protocol was posted on GSK's Clinical Study Register (www.gsk-clinicalstudyregister.com GSK Study ID 114617) and on the US National Library of Medicine NIH website www.clinicaltrials.gov (NCT01521286). 
Table 1 Patient demographics in the overall cohort

\begin{tabular}{|c|c|c|c|c|c|c|c|c|c|c|c|c|}
\hline & \multicolumn{2}{|c|}{$\begin{array}{l}\text { 50-59 YOA } \\
(N=137)\end{array}$} & \multicolumn{2}{|c|}{$\begin{array}{l}\text { 60-64 YOA } \\
(N=90)\end{array}$} & \multicolumn{2}{|c|}{$\begin{array}{l}\text { 65-69 YOA } \\
(N=100)\end{array}$} & \multicolumn{2}{|c|}{$\begin{array}{l}70-79 \text { YOA } \\
(N=158)\end{array}$} & \multicolumn{2}{|c|}{$\begin{array}{l}\geq 80 \text { YOA } \\
(N=60)\end{array}$} & \multicolumn{2}{|c|}{$\begin{array}{l}\text { Overall } \\
\begin{array}{l}\geq 50 \text { YOA } \\
(N=545)\end{array}\end{array}$} \\
\hline & $n$ & $\%$ & $n$ & $\%$ & $n$ & $\%$ & $n$ & $\%$ & $n$ & $\%$ & $n$ & $\%$ \\
\hline \multicolumn{13}{|l|}{ Gender } \\
\hline Male & 59 & 43.1 & 38 & 42.2 & 47 & 47.0 & 69 & 43.7 & 20 & 33.3 & 233 & 42.8 \\
\hline Female & 78 & 56.9 & 52 & 57.8 & 53 & 53.0 & 89 & 56.3 & 40 & 66.7 & 312 & 57.2 \\
\hline \multicolumn{13}{|l|}{ Employment } \\
\hline Employed & 87 & 63.5 & 34 & 37.8 & 1 & 1.0 & - & - & - & - & 122 & 22.4 \\
\hline Unemployed & 20 & 14.6 & 12 & 13.3 & - & - & - & - & 2 & 3.3 & 34 & 6.2 \\
\hline Retired & 12 & 8.8 & 32 & 35.6 & 87 & 87.0 & 137 & 86.7 & 56 & 93.3 & 324 & 59.4 \\
\hline Other (unpaid) & 18 & 13.1 & 12 & 13.3 & 12 & 12.0 & 21 & 13.3 & 2 & 3.3 & 65 & 11.9 \\
\hline \multicolumn{13}{|l|}{ Age } \\
\hline Mean & 54.6 & & 61.8 & & 66.9 & & 74.2 & & 83.5 & & 66.9 & \\
\hline SD & 2.65 & & 1.44 & & 1.42 & & 2.92 & & 2.78 & & 9.68 & \\
\hline Median & 55 & & 62 & & 67 & & 74 & & 83 & & 67 & \\
\hline Range & $50-59$ & & $60-64$ & & $65-69$ & & $70-79$ & & $80-91$ & & $50-91$ & \\
\hline
\end{tabular}

$n$ total number in each age group, $n / \%$ number/percentage in each category, $S D$ standard deviation, $Y O A$ years of age

\section{RESULTS}

\section{Patient Demographics}

A total of 545 patients with $\mathrm{HZ}$ were enrolled across the four GP networks and included in the HRQL and economic analyses: Madrid $(n=229)$, Catalonia $(n=146)$, Publica Valencia $(n=93)$, and Pau Valencia $(n=77)$. The mean (SD) age was 66.9 (9.7) years (range 50-91 years); $57.2 \%$ were women. A total of 324 patients (59.4\%) were retired, $122(22.4 \%)$ were employed/self-employed, and 34 (6.2\%) unemployed; 65 patients (11.9\%) stated "other" as their employment status (35 of whom were at least 65 years of age) (Table 1 ).

Of these 545 patients with $\mathrm{HZ}, 470$ (86.2\%) had no HZ complications occurring within the first 90 days of the study, and 25 patients (4.6\%) developed PHN during the study period (and were followed up beyond day 90). A further 50 patients $(9.2 \%)$ had one or more HZ-related complications (excluding PHN) occurring within the first 90 days of the study: chiefly cutaneous complications (including bacterial superinfection and disseminated varicella-zoster virus) and neurological (mainly peripheral nerve palsies; no cases of zoster-associated meningoencephalitis were reported) and ocular or ophthalmic complications (chiefly keratitis). No visceral complications were reported.

\section{Questionnaire Compliance}

The proportion of patients completing the ZBPI and EQ-5D questionnaires varied across specific time points. ZBPI questionnaires were available for $291 / 545$ patients $(53.4 \%)$ at day 0, for $240 / 545$ patients $(44.0 \%)$ at day 30 , and for 209/545 patients (38.3\%) at day 90. Subsequently, of the 25 patients with PHN, compliance was $16.0 \%(4 / 25)$ at day 180 and $21.4 \%$ (3/ 

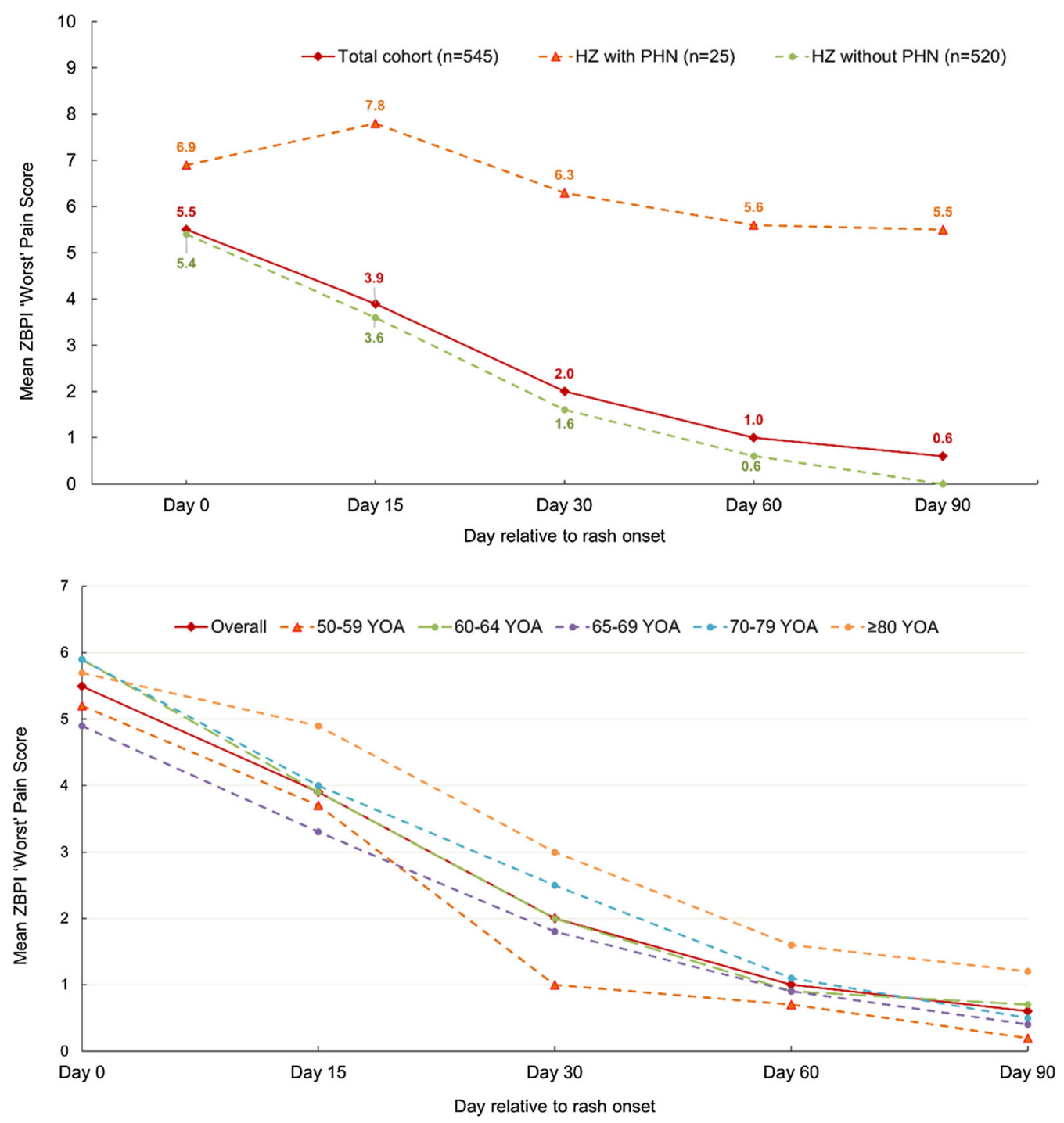

Fig. 1 ZBPI worst pain score over time until day 90 by PHN status and by age. $n$ number of subjects, PHN postherpetic neuralgia, YOA years of age, ZBPI Zoster Brief Pain Inventory

14) at day 270. Compliance was the highest in those aged 80 years or more (Supplementary Fig. 1). Compliance was greater for the EQ-5D questionnaire. At day 0, EQ-5D questionnaires were available for 307/545 patients (56.3\%) and compliance increased during study follow-up: $83.3 \%(454 / 545)$ at day 30 and $80.9 \%(441 / 545)$ at day 90 , with some decline thereafter.

\section{HRQL Analysis Based on ZBPI Instrument}

At day 0, 261/286 patients with an available ZBPI worst pain score $(91.3 \%)$ reported any pain while 229/286 (80.1\%) reported moderate/severe pain (worst pain score $\geq 3$ ) and $132 / 286$ (46.2\%) reported severe pain (worst pain score $\geq 7$ ). The mean (SD) worst pain score at day 0 for the overall cohort was 5.50 (2.96). Patients who developed PHN had a higher mean (SD) worst pain score at day 0 than those who did not develop PHN: 6.90 (1.67) versus 5.40 (3.02). At day 90, the mean (SD) worst pain scores for 


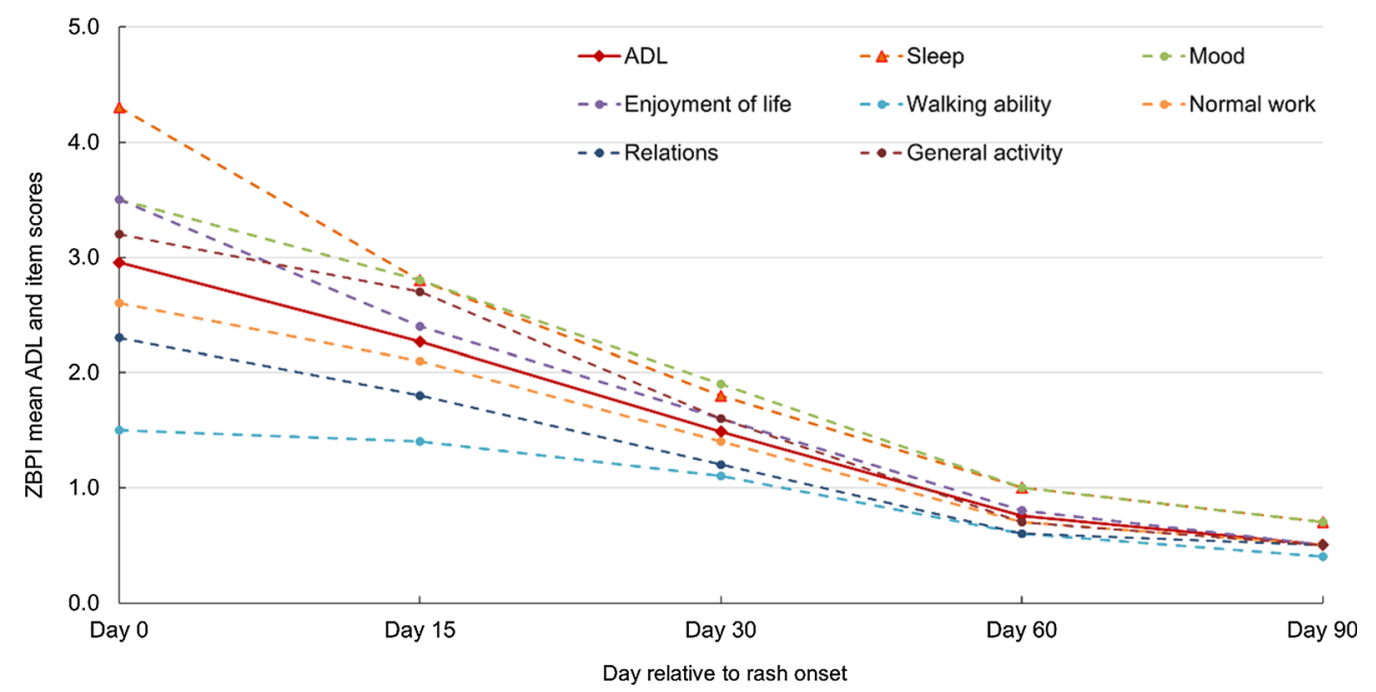

Fig. 2 Mean Zoster Brief Pain Inventory (ZBPI) interference with activities of daily living (ADL) over the first 90 days after rash onset

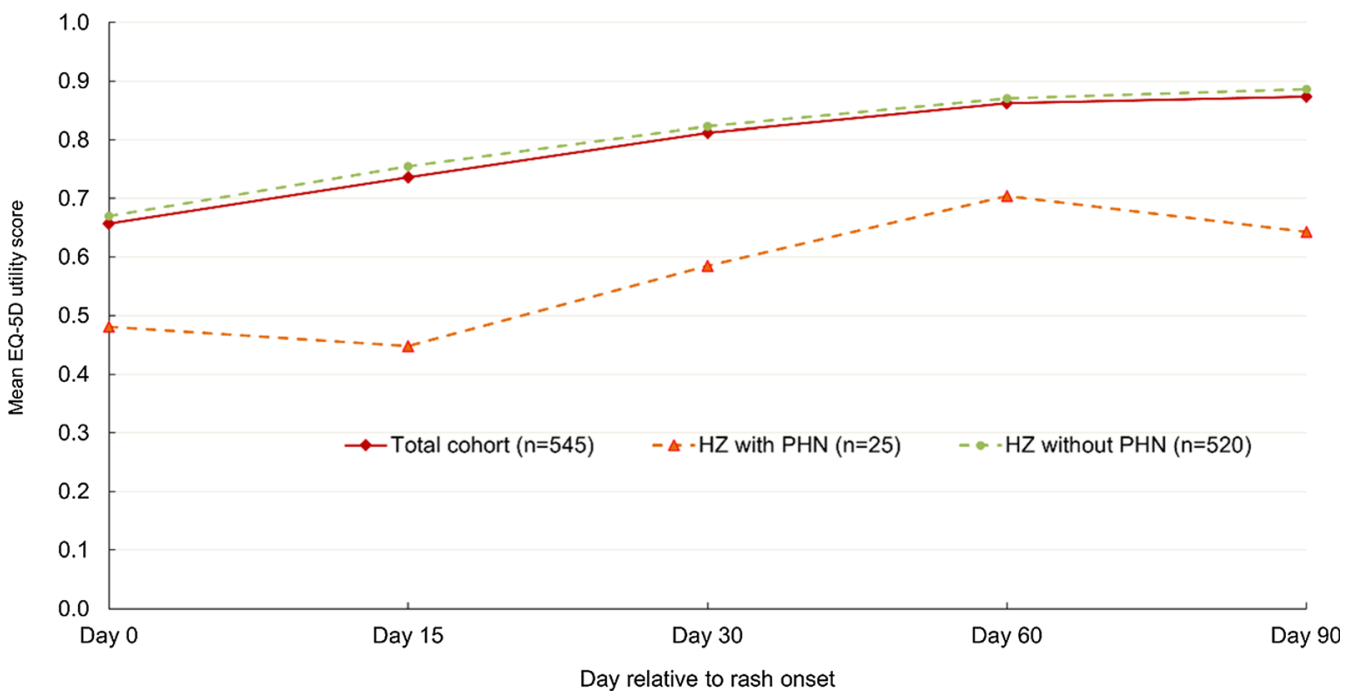

Fig. 3 Mean EQ-5D utility scores over time by PHN status. EQ-5D EuroQoL-5 Dimension questionnaire, $n$ number of subjects, PHN postherpetic neuralgia

the overall cohort and in those who did not develop PHN were 0.60 (1.75) and 0.0 (0.37), respectively; in patients with $\mathrm{PHN}$, at day 90 , the mean (SD) worst pain score was 5.50 (1.93) (Fig. 1). In the overall study cohort, the mean worst pain scores appeared to diminish more slowly in the older age groups (Fig. 1).

Mean and least-square (LS) mean ZBPI ADL scores for the overall $\mathrm{HZ}$ patient cohort are detailed in Table S3 in the electronic supplementary material. The estimated LS mean (SE) for pain interference with ADLs was approximately $2.91 \quad(0.16)$ at day 0 and decreased steadily during the study period to 0.55 (0.10) at day 90 (Table S3). Sleep was the item most affected by the HZ episode throughout the 90-day study period with a mean (SD) score of 4.30 (3.63) at day 0, although the impact on sleep subsequently declined (Fig. 2). At day 0, 203/283 patients (71.7\%) with an 


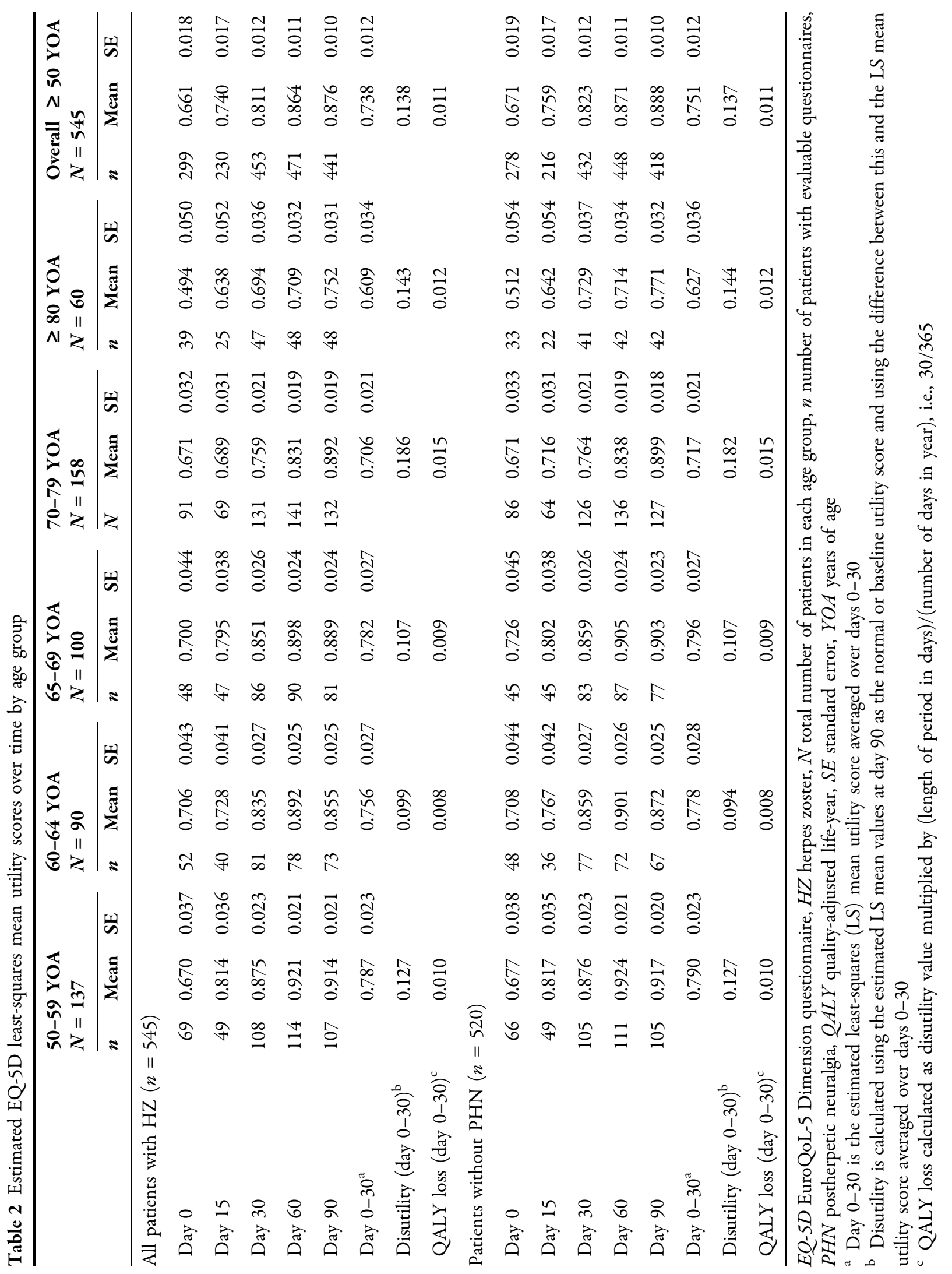


Table 3 Direct medical costs $(€)$ by component and total costs by complication category according to analytic perspective

\begin{tabular}{|c|c|c|c|c|c|c|c|c|c|c|c|c|}
\hline \multirow[t]{2}{*}{ Perspective } & \multicolumn{2}{|c|}{$\begin{array}{l}50-59 \text { YOA } \\
N=137\end{array}$} & \multicolumn{2}{|c|}{$\begin{array}{l}60-64 \text { YOA } \\
N=90\end{array}$} & \multicolumn{2}{|c|}{$\begin{array}{l}65-69 \text { YOA } \\
N=100\end{array}$} & \multicolumn{2}{|c|}{$\begin{array}{l}70-79 \text { YOA } \\
N=158\end{array}$} & \multicolumn{2}{|c|}{$\begin{array}{l}\geq 80 \text { YOA } \\
N=60\end{array}$} & \multicolumn{2}{|c|}{$\begin{array}{l}\text { Overall } \geq 50 \\
\text { YOA } \\
N=545\end{array}$} \\
\hline & $n$ & $\begin{array}{l}\text { Mean } \\
\text { (SD) }\end{array}$ & $n$ & $\begin{array}{l}\text { Mean } \\
\text { (SD) }\end{array}$ & $n$ & $\begin{array}{l}\text { Mean } \\
(\text { SD) }\end{array}$ & $n$ & $\begin{array}{l}\text { Mean } \\
(\text { SD) }\end{array}$ & $n$ & $\begin{array}{l}\text { Mean } \\
\text { (SD) }\end{array}$ & $n$ & $\begin{array}{l}\text { Mean } \\
(\text { SD) }\end{array}$ \\
\hline \multicolumn{13}{|c|}{ Direct medical costs } \\
\hline \multicolumn{13}{|l|}{ GP visits } \\
\hline $\mathrm{HCS} /$ societal & 137 & $83.8(41.1)$ & 90 & $\begin{array}{l}105.2 \\
(73.9)\end{array}$ & 100 & $\begin{array}{l}103.5 \\
\quad(118.7)\end{array}$ & 158 & $\begin{array}{l}119.8 \\
\quad(127.1)\end{array}$ & 60 & $\begin{array}{l}143.2 \\
\quad(131.2)\end{array}$ & 545 & $\begin{array}{l}107.9 \\
\quad(103.7)\end{array}$ \\
\hline Range & & $63-251$ & & $63-376$ & & $63-1006$ & & $63-878$ & & $63-627$ & & $63-1066$ \\
\hline \multicolumn{13}{|l|}{ Medications } \\
\hline HCS & 134 & $38.3(23.2)$ & 88 & $53.6(33.3)$ & 100 & $67.3(39.3)$ & 153 & $72.8(52.1)$ & 57 & $82.5(54.1)$ & 532 & $60.9(43.9)$ \\
\hline Range & & $152-304$ & & $0-161$ & & $2-176$ & & $0-277$ & & $0-238$ & & $0-277$ \\
\hline Societal & 134 & $77.1(45.2)$ & 88 & $88.6(49.9)$ & 100 & $83.7(45.1)$ & 153 & $92.2(61.9)$ & 57 & $\begin{array}{l}101.1 \\
\quad(58.9)\end{array}$ & 532 & $87.2(53.1)$ \\
\hline Range & & $2-244$ & & $2-377$ & & $2-196$ & & $1-409$ & & $2-287$ & & $1-409$ \\
\hline \multicolumn{13}{|c|}{ Procedures/lab tests } \\
\hline HCS/societal & 12 & $52.4(32.1)$ & 1 & $64.2(-)$ & 3 & $66.9(55.4)$ & 13 & $48.4(39.0)$ & 3 & $51.4(33.9)$ & 32 & $52.4(35.5)$ \\
\hline Range & & $13-128$ & & - & & $13-124$ & & $13-150$ & & $13-77$ & & $13-150$ \\
\hline \multicolumn{13}{|l|}{ Specialist visits } \\
\hline HCS/societal & 7 & $\begin{array}{l}173.5 \\
(57.4)\end{array}$ & 3 & $\begin{array}{l}202.5 \\
(87.7)\end{array}$ & 3 & $\begin{array}{l}252.6 \\
\quad(174.5)\end{array}$ & 7 & $\begin{array}{l}152.0 \\
(118.5)\end{array}$ & 6 & $\begin{array}{l}365.0 \\
(253.9)\end{array}$ & 26 & $\begin{array}{l}224.4 \\
\quad(164.9)\end{array}$ \\
\hline Range & & $152-304$ & & $152-304$ & & $152-454$ & & $12-388$ & & $152-822$ & & $12-822$ \\
\hline \multicolumn{13}{|c|}{ Hospital admissions } \\
\hline HCS/societal & 1 & $2925(-)$ & 1 & $2925(-)$ & 1 & $2925(-)$ & 7 & $2925(-)$ & 1 & $2925(-)$ & 11 & $2925(-)$ \\
\hline Range & & - & & - & & - & & - & & - & & - \\
\hline \multicolumn{13}{|l|}{ Overall mean ${ }^{\mathrm{a}}$} \\
\hline HCS & 137 & $\begin{array}{l}156.0 \\
(259.7)\end{array}$ & 90 & $\begin{array}{l}197.6 \\
(319.7)\end{array}$ & 100 & $\begin{array}{l}209.6 \\
\quad(402.3)\end{array}$ & 158 & $\begin{array}{l}330.6 \\
\quad(663.5)\end{array}$ & 60 & $\begin{array}{l}309.3 \\
\quad(453.3)\end{array}$ & 545 & $\begin{array}{l}240.2 \\
\quad(466.4)\end{array}$ \\
\hline Range & & $63-3047$ & & $63-3053$ & & $63-3818$ & & $63-4084$ & & $63-3073$ & & $63-4084$ \\
\hline Societal & 137 & $\begin{array}{l}193.9 \\
(264.7)\end{array}$ & 90 & $\begin{array}{l}231.8 \\
\quad(326.9)\end{array}$ & 100 & $\begin{array}{l}226.0 \\
(405.5)\end{array}$ & 158 & $\begin{array}{l}349.5 \\
\quad(670.0)\end{array}$ & 60 & $\begin{array}{l}327.0 \\
(457.3)\end{array}$ & 545 & $\begin{array}{l}265.8 \\
(470.5)\end{array}$ \\
\hline Range & & $63-3106$ & & $63-3119$ & & $65-3837$ & & $63-4289$ & & $63-3083$ & & $63-4289$ \\
\hline \multicolumn{13}{|c|}{ Total costs by complication category ${ }^{\mathrm{a}, \mathrm{b}}$} \\
\hline \multicolumn{13}{|c|}{$\mathrm{HZ}$ without PHN or any other complication } \\
\hline HCS & 127 & $131(69)$ & 76 & $185(342)$ & 88 & $168(178)$ & 130 & $237(471)$ & 49 & $237(426)$ & 470 & $187(328)$ \\
\hline Range & & $63-423$ & & $63-3053$ & & $64-1708$ & & $63-3219$ & & $63-3073$ & & $63-3219$ \\
\hline Societal & 127 & $239(390)$ & 76 & $283(512)$ & 88 & $184(186)$ & 130 & $255(470)$ & 49 & $251(425)$ & 470 & $242(412)$ \\
\hline Range & & $63-4046$ & & $63-3433$ & & $65-1772$ & & $63-3228$ & & $63-3083$ & & $63-4046$ \\
\hline \multicolumn{13}{|l|}{ With PHN } \\
\hline HCS & 3 & 99 (18) & 6 & $310(191)$ & 4 & $\begin{array}{l}1124 \\
\quad(1798)\end{array}$ & 6 & $750(1233)$ & 6 & $519(464)$ & 25 & $571(937)$ \\
\hline Range & & $87-120$ & & $66-538$ & & $168-3818$ & & $110-3229$ & & $108-1211$ & & $66-3818$ \\
\hline
\end{tabular}


Table 3 continued

\begin{tabular}{|c|c|c|c|c|c|c|c|c|c|c|c|c|}
\hline \multirow[t]{2}{*}{ Perspective } & \multicolumn{2}{|c|}{$\begin{array}{l}50-59 \\
\text { YOAN = } 137\end{array}$} & \multicolumn{2}{|c|}{$\begin{array}{l}60-64 \\
\text { YOAN =90 }\end{array}$} & \multicolumn{2}{|c|}{$\begin{array}{l}65-69 \\
\text { YOAN = } 100\end{array}$} & \multicolumn{2}{|c|}{$\begin{array}{l}70-79 \\
\text { YOAN = } 158\end{array}$} & \multicolumn{2}{|c|}{$\begin{array}{l}\geq 80 \\
\text { YOAN }=60\end{array}$} & \multicolumn{2}{|c|}{$\begin{array}{l}\text { Overall } \geq 50 \\
\text { YOAN }=545\end{array}$} \\
\hline & $n$ & $\begin{array}{l}\text { Mean } \\
\text { (SD) }\end{array}$ & $\bar{n}$ & $\begin{array}{l}\text { Mean } \\
\text { (SD) }\end{array}$ & $n$ & $\begin{array}{l}\text { Mean } \\
\text { (SD) }\end{array}$ & $\bar{n}$ & $\begin{array}{l}\text { Mean } \\
\text { (SD) }\end{array}$ & $\bar{n}$ & $\begin{array}{l}\text { Mean } \\
\text { (SD) }\end{array}$ & $n$ & $\begin{array}{l}\text { Mean } \\
\text { (SD) }\end{array}$ \\
\hline Societal & 3 & $172(99)$ & 6 & $797(1159)$ & 4 & $\begin{array}{l}1137 \\
\quad(1802)\end{array}$ & 6 & $766(1240)$ & 6 & $562(498)$ & 25 & $712(1065)$ \\
\hline Range & & $111-287$ & & $66-3116$ & & $180-3837$ & & $116-3255$ & & $113-1355$ & & $66-3837$ \\
\hline \multicolumn{13}{|c|}{ HZ with complications (excluding PHN) } \\
\hline HCS & 7 & $635(1070)$ & 8 & $232(82)$ & 8 & $210(89)$ & 22 & $769(1123)$ & 5 & $770(439)$ & 50 & $575(872)$ \\
\hline Range & & $87-3047$ & & $142-338$ & & $79-308$ & & $63-4084$ & & $474-1525$ & & $63-4084$ \\
\hline Societal & 7 & $678(1078)$ & 8 & $265(95)$ & 8 & $235(87)$ & 22 & $794(1149)$ & 5 & $786(437)$ & 50 & $603(887)$ \\
\hline Range & & $111-3106$ & & $158-399$ & & $81-321$ & & $78-4289$ & & $494-1540$ & & $78-4289$ \\
\hline \multicolumn{13}{|c|}{ All patients with $\mathrm{HZ}$} \\
\hline HCS & 137 & $156(260)$ & 90 & $198(320)$ & 100 & $210(402)$ & 158 & $331(663)$ & 60 & $309(453)$ & 545 & $240(466)$ \\
\hline Range & & $63-3047$ & & $63-3053$ & & $64-3818$ & & $63-4084$ & & $63-3073$ & & $63-4084$ \\
\hline Societal & 137 & $260(449)$ & 90 & $316(560)$ & 100 & $226(405)$ & 158 & $349(670)$ & 158 & $327(457)$ & 545 & $296(535)$ \\
\hline Range & & $63-4046$ & & $63-3433$ & & $65-3837$ & & $63-4289$ & & $63-3083$ & & $63-4289$ \\
\hline
\end{tabular}

$G P$ general practitioner, $H C S$ healthcare system, $H Z$ herpes zoster, mean mean cost in $€$ averaging only over the patients generating this cost component, $n$ number of patients generating this cost component, $N$ number of patients enrolled in this age group, $P H N$ postherpetic neuralgia, $Y O A$ years of age

a The mean cost in $€$ by averaging each cost component over all 545 patients and adding over all the cost components

b Indirect costs include productivity loss due to work absence for patients still working and caregiver productivity loss averaged over all patients in the relevant category to estimate the average total societal cost for each $\mathrm{HZ}$ category

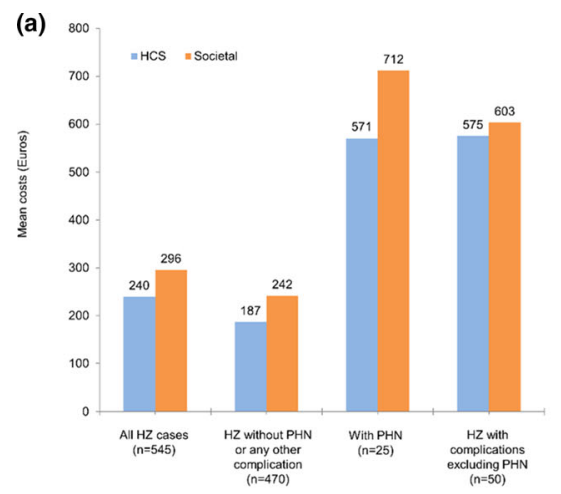

Fig. 4 Mean costs by payer perspective and complication category (a) and distribution of direct medical costs per herpes zoster episode from the HCS perspective (b) and medical costs and indirect costs from the societal (b)

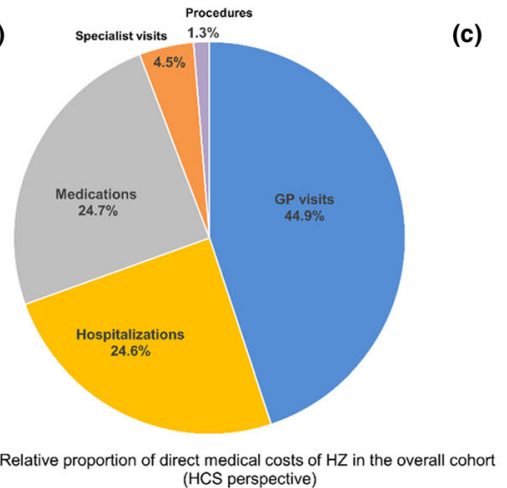

(c)

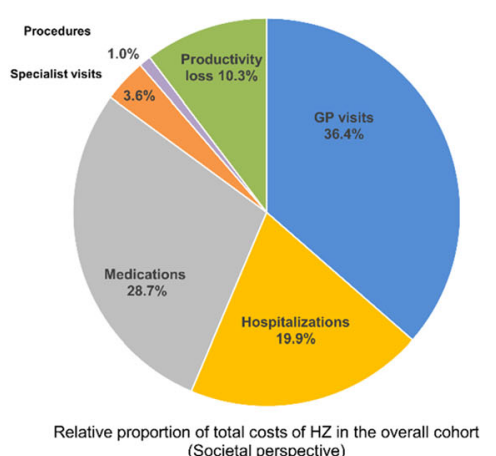

perspective (c). HCS healthcare system, HZ herpes zoster, GP general practitioner, $n$ number of patients, PHN postherpetic neuralgia available ZBPI sleep score reported any interference with sleep (score $\geq 1$ ) and 100/283 (35.3\%) reported severe interference (score $\geq 7$ ). Other items with a mean score of $\geq 3$ at day 0 were mood, enjoyment of life, and general activity (Fig. 2). 


\section{HRQL Analysis Using EQ-5D}

Mean EQ-5D utility scores were available for $299 / 545$ patients $(54.9 \%)$ at day $0,453 / 545$ patients $(83.1 \%)$ at day 30 , and $441 / 545$ patients $(80.9 \%)$ at day 90 . Estimated mean EQ$5 \mathrm{D}$ utility scores over the study period for the overall cohort, and for those patients with $\mathrm{HZ}$ without PHN and for those with PHN are shown in Fig. 3 and detailed in Table S4 in the electronic supplementary material. Mean EQ-5D utility scores in patients who developed PHN were lower by approximately 0.2 than the corresponding mean score for patients with $\mathrm{HZ}$ without PHN at each time point from day 0 to day 90 (Fig. 3 and Table S4 in the electronic supplementary material).

Estimated LS mean (SE) EQ-5D utility scores for the overall cohort and for patients with $\mathrm{HZ}$ without PHN are shown in Table 2. The LS mean (SE) utility score for the overall $\mathrm{HZ}$ patient cohort increased from $0.661(0.018)$ at day 0 to $0.876(0.010)$ at day 90 , with an estimated mean (SE) over the first month after $\mathrm{HZ}$ onset of 0.738 (0.012) (Table 2). If it is assumed that the day 90 scores may reflect or act as a proxy for the normal baseline EQ-5D utility score for patients prior to the HZ episode (an approach used in similar studies from Germany and Italy $[25,26])$, then an overall utility loss (or disutility) during the first month of the $\mathrm{HZ}$ episode can be estimated. For the overall $\mathrm{HZ}$ patient cohort, the estimated disutility was 0.138 in the first 30 days of the $\mathrm{HZ}$ episode. Disutility was the greatest in patients aged 70-79 years, with a mean disutility of 0.186 in the first month. A similar pattern in LS mean (SE) utility scores across the study period was observed in those patients with HZ who did not develop PHN, with similar estimations for disutility (0.137) in the first 30 days of the HZ episode (Table 2).

\section{Healthcare Resource Utilization and Costs}

Healthcare resource utilization information was available for all 545 participants. Eleven patients $(2.0 \%)$ were hospitalized, and five patients $(0.9 \%)$ had a total of seven emergency room visits. For 30 patients (5.5\%), a total of 51 specialist visits were recorded, which included five patients with a total of seven emergency room visits; three patients required a total of 22 nursing visits, and nine patients visited an ophthalmologist (each for a single consultation).

A total of 938 outpatient GP visits were reported; a mean of approximately 1.7 visits per HZ episode for the overall cohort; 545 occurred at the initial visit, then 369 visits involving 173 patients between day 0 and day 90, and 24 visits involving 11 patients (all with PHN) between day 90 and day 270. A total of 16 patients had lost work days, corresponding to $3 \%$ of all patients and $13.1 \%$ of patients in employment; with a mean work loss of 9.9 days (median 6.5) during their $\mathrm{HZ}$ episode. The caregivers of eight patients lost an average of 1.3 paid workdays (median 1.0). The mean costs of these productivity work losses from a societal perspective were $€ 66.3$ per patient aged 50-59 years and $€ 84.2$ per patient aged $60-64$ years. The indirect costs from a societal perspective associated with these work losses averaged across the total cohort were $€ 30.5$ per patient.

Systemic antivirals were prescribed for $85 \%$ of the patients; most frequently valaciclovir $(28.4 \%)$, brivudine $(27.0 \%)$, and acyclovir (24.4\%). Analgesics were prescribed for $55 \%$ of patients, with pregabalin being prescribed for $8.3 \%$ of patients (Table S5 in the electronic supplementary material).

The mean (SD) costs per HZ episode in the overall cohort ( $n=545$ ) were $€ 240$ ( $€ 466$; range $€ 63-4084)$ from the HCS payer perspective and $€ 296$ (€535; range €63-4289) from the societal perspective (Table 3 and Fig. 4). Costs were the highest in the 70-79 years age group and were higher for women than for men from both perspectives (Table $S 6$ in the electronic supplementary material). GP visits made up $45 \%$ of the direct medical costs per HZ episode, with medication and hospitalization costs each accounting for $25 \%$ of direct medical costs from the HCS perspective. The relative contribution of these costs and also of those indirect costs associated with productivity loss to total costs of $\mathrm{HZ}$ from the societal perspective in our overall HZ cohort are shown in Fig. 4.

For patients without any HZ-related complications the mean (SD) costs were $€ 187$ (€328; 
range €63-3219) from the HCS payer perspective and $€ 242$ ( $€ 412$; range $€ 63-4046$ ) from the societal perspective. For patients with $\mathrm{PHN}$ the mean (SD) costs from the payer perspective amounted to $€ 571$ (€937; range €66-3818) and $€ 712$ ( $€ 1065$; range $€ 66-3837)$ from the societal perspective. For those patients with complications other than PHN the mean (SD) costs were $€ 575$ (€872; range €63-4084) and €603 (€887; range $€ 78-4289$ ) from the payer/societal perspectives, respectively (Table 3 and Fig. 4a). For these patients with non-PHN complications, the mean (SD) costs for those with cutaneous complications were $€ 576 \quad(€ 823$; range $€ 76-3120)$ from the payer perspective and $€ 607$ (€822; range $€ 78-3134)$ from the societal perspective. For those with ophthalmic complications, the mean (SD) costs were $€ 1107$ ( $€ 1164$; range $€ 63-3047)$ and $€ 1142 \quad(€ 1171$; range $€ 120-3106)$ from the HCS payer/societal perspectives, respectively; and for neurologic complications (a single patient) $€ 4084$ from a payer perspective and $€ 4289$ from a societal perspective (Table S7 in the electronic supplementary material).

\section{DISCUSSION}

We found that pain associated with the initial HZ episode had a clear impact on the patients' HRQL and interference in ADLs; at day 0, 80.1\% of patients had moderate or severe HZ "worst" pain and $46.2 \%$ had severe "worst" pain. Acute HZ pain had an impact on the patients' ADLs, in particular sleep disturbance with $35.3 \%$ of patients reporting severe interference on sleep score at day 0 (Fig. 2). For most patients, interference with ADL reduced within 30 days after $\mathrm{HZ}$ rash onset, with mean scores between 1 and 2 for all the ZBPI ADL items at this time point. EQ-5D scores were also impacted in the acute $\mathrm{HZ}$ phase, with a mean disutility of 0.138 in the first 30 days of the HZ episode in the overall HZ patient cohort, which represents a quality-adjusted life-year (QALY) loss of 0.011 in the first month (and with greater disutility and QALY loss in older patients) (Table 2).

In our cohort, 25 patients (4.6\%) developed $\mathrm{PHN}$, and mean ZBPI "worst" pain scores at day 0 in patients who developed PHN were higher than in those who did not (6.9 and 5.4, respectively) and remained above 5.0 during the first 90 days, whereas "worst" pain scores fell below 2.0 after 1 month in patients with $\mathrm{HZ}$ without subsequent PHN (Fig. 1). HRQL was also lower in patients who developed PHN, with EQ-5D utility scores at day 0 around 0.2 lower than in patients without PHN, with this difference maintained over the entire 90-day followup period (patients without PHN were not followed beyond day 90) (Fig. 3).

Our estimate of $4.6 \%$ of patients with $\mathrm{HZ}$ developing PHN is lower than that reported in other studies from Spain. An extensive retrospective analysis of primary care records evaluating the risk of $\mathrm{HZ}$ in patients aged 50 years or older in the Valencia region reported that 13,658 out of 87,086 patients with HZ (15.7\%) developed PHN [19]. In Catalonia, PHN has been reported to occur in $12.3 \%$ of patients with $\mathrm{HZ}$ aged $50-59$ years and in $17.5 \%$ in those aged 70 years or older [20]. In our study, the proportion was based on the total number of patients in the overall study cohort $(N=545)$ rather than the number of patients with an actual pain assessment after day $90(N=212)$. If we limit our estimate to those patients with an assessment on or after day 90, the percentage of patients at least 50 years old with $\mathrm{HZ}$ who developed PHN increases to $11.8 \%$ which is more in keeping with these previous data from Spain.

Questionnaire compliance (in terms of response rates for completed questionnaires) in this study was lower than observed for other studies which used a similar approach to evaluating $\mathrm{HZ}$ impact on HRQL $[25,26]$. We had available ZBPI and EQ-5D scores for only around $50 \%$ of our cohort at initial assessment, and so our observations on pain and interference in ADLs and impact on HRQL may not be wholly representative of the overall study population. The differential response rate between ZBPI and EQ-5D at subsequent study time points is also unusual; however, one explanation for the greater compliance with the EQ-5D questionnaire may be that this was due to telephone administration [37]. We are uncertain as to the impact of low compliance rates on our 
overall cohort's HRQL outcomes and the nature of any potential sampling bias associated with this; our findings on HZ impact on HRQL should be considered in light of these limitations. Nevertheless, our HRQL results are consistent with those of previous studies that used the same ZBPI and EQ-5D instruments for assessing the impact of HZ and PHN on HRQL $[5,8,9,27,38,39]$. Although HRQL data in Spanish patients with $\mathrm{HZ}$ are scarce, a recent Italian study using similar methodology reported comparable impact of HZ-related pain on ADLs and EQ-5D scores, with similar disutility during the first month following rash onset, and with the greatest impact observed in those patients subsequently developing PHN [26]. This would suggest that missing data may be missing completely at random.

Looking at healthcare resource use within our cohort, the mean number of primary care visits per patient due to the HZ episode was 1.7 visits, somewhat lower than that reported by Cebrián-Cuenca et al. in a previous study from Spain which also prospectively evaluated resource use and allied costs of $\mathrm{HZ}$ and PHN treated in primary care in Valencia (which reported an average of 2.4 GP visits) [21], while a later retrospective study from Valencia by Muñoz-Quiles et al. reported data indicating an average of 2.0 cases per patient [19]. The mean number of additional specialist or nursing consultations or emergency room visits (0.09 per patient) is also lower than that reported by Cebrián-Cuenca et al. (where a mean number of 0.29 specialist visits per patient and a further 0.31 nursing or other professional visits per patient were reported) [21]. The proportion of our cohort hospitalized (2.0\%) is similar to that reported by Salleras et al. (1.5\%) in a previous Spanish study [20], although others report lower rates: $1.2 \%$ in the extensive retrospective analysis from Valencia [19], whereas in the cohort reported by Cebrián-Cuenca et al., none of the 130 patients were hospitalized for $\mathrm{HZ}$ [21]. The proportion of our study cohort receiving systemic antivirals (95\%) is broadly comparable to that reported by Cebrián-Cuenca et al. in their cohort (91\%) [21].

Our analysis of the costs of $\mathrm{HZ}$ and related complications confirms that $\mathrm{HZ}$ presents a substantial economic burden. Note that unlike the HRQL aspect of the study, cost data was recorded by GPs at the initial visit or on subsequent visits, supplemented with data from additional medical providers when relevant and entered into case report forms throughout the study, and so was not dependent on ZBPI and EQ-5D questionnaire completion. We found a mean direct medical cost per patient of $€ 240$ from the HCS payer perspective and $€ 266$ from a societal perspective, and overall disease costs of $€ 240$ from the HCS payer perspective and €296 from a societal perspective. Costs were dependent upon development of complications: the lowest in uncomplicated $\mathrm{HZ}$, greater in patients who developed PHN, and the highest in those with other non-PHN complications (Fig. 4).

Although one should be cautious about making cost comparisons, our costs were lower than those previously reported from Spain. In their study, Cebrián-Cuenca and colleagues estimated total costs per HZ episode (which excluded hospitalizations) of $€ 309$ and $€ 378$ from the payer and societal perspectives, respectively [21]. In that study, costs also varied depending on PHN status, with mean costs per patient of $€ 821$ in those with PHN compared with $€ 307$ in those without PHN [21]. In a retrospective study from Catalonia, Salleras and colleagues estimated the direct healthcare costs for patients with $\mathrm{HZ}$ presenting in the dermatology outpatient unit of a hospital, where the mean direct medical cost per patient was $€ 302$ in cases of $\mathrm{HZ}$ that did not evolve to PHN and $€ 917$ for those who subsequently PHN [20]. Another primary care retrospective study from Catalonia reported overall (direct and indirect) costs of $€ 1827$ for patients with PHN and $€ 457$ for patients with uncomplicated HZ [22]. In all these studies, costs were greater in older patients.

Our study was not designed to monitor the evolution of $\mathrm{HZ}$ costs over specific time periods, which may be considered a limitation. However, the great majority of resources used and estimated costs we report were incurred within the first 90 days (as only those patients with PHN we followed beyond this point). Furthermore, much of the resource use and allied medical costs relate to services provided the 
acute HZ episode (initial GP visit, antiviral medication treatment, HZ hospitalization, etc.), and would have been incurred within the first 30 days, although it may be expected that patients with complications and with persistent HZ-associated pain would continue to incur further cumulative costs. This would be consistent with other data. For example, in their resource use and cost analysis, the majority of the primary care services and allied costs reported by Cebrián-Cuenca et al. were incurred within the first month [21].

From these studies, and as seen in the present study, it seems clear that HZ carries a significant economic burden and that direct medical costs are greater in older patients, with a common finding that PHN development substantially increases direct and societal $\mathrm{HZ}$ costs. However, as reported elsewhere, when considering the overall cost of disease at a population level, the overall cost is higher for patients with uncomplicated $\mathrm{HZ}$, primarily a result of the higher incidence rates of uncomplicated HZ [10].

The study has certain limitations relating to the cost analysis. This study was carried out in a GP setting with data on resource utilization derived from GPs' own clinical records and from external sources (i.e., information provided by patients or from external clinical institutions and physicians); additional visits to other specialists, prescribed medications, and hospitalizations may have occurred without being reported to the study GP and so not recorded in the database. Our results should be considered in the context of such uncertainty (which on balance may be an underestimation of actual costs). Study strengths include its prospective design which evaluated a relatively large cohort of patients with $\mathrm{HZ}$ presenting in primary care.

\section{CONCLUSION}

In Spain, HZ and HZ-related complications such as PHN are associated with impacted HRQL for patients at least 50 years old and represent a substantial economic burden for payers (HCS) and at a societal level.

\section{ACKNOWLEDGEMENTS}

The authors would like to thank all study participants, and also all local investigators who contributed to data collection and other programmatic aspects of this study. They also acknowledge the contribution of Carla Talarico (previously at GSK) for providing feedback during manuscript development.

Funding. This work was supported by GlaxoSmithKline Biologicals SA who funded this study (ClinicalTrials.gov NCT01521286) and was involved in all stages of study conduct, including analysis of the data. GlaxoSmithKline Biologicals SA also took in charge all costs associated with publication of this manuscript.

Authorship. All named authors have contributed to the design/acquisition of data or analysis and data interpretation. All provided substantial intellectual and scientific input during manuscript development, critically reviewing the content, revising the manuscript and giving final approval before submission. The work described was carried out in accordance with the ICMJE recommendations for conducting, reporting, editing and publishing scholarly work in medical journals.

Medical Writing, Editorial and Other Assistance. The authors would like to thank Business \& Decision Life Sciences platform for editorial assistance and manuscript coordination, on behalf of GSK. Matthieu Depuydt, Aurélie Roth and Elena Chaves Rodriguez coordinated manuscript development and editorial support; Niels Neymark of Neymark Scientific Writing SCS and Iain O'Neill (freelance) provided writing assistance on behalf of GSK. The assistance was funded by GlaxoSmithKline Biologicals SA.

Prior Presentation. Poster presentation made at the International Society for Pharmacoeconomics and Outcomes Research-20th Annual European Congress (Nov 4-8, 2017; Glasgow, Scotland, UK). 
Disclosures. Javier Díez-Domingo reports study grant and personal fees from the GSK group of companies. Sean Matthews is a freelance consultant for the GSK group of companies. Desmond Curran, Maria del Rosario Cambronero and Juan-Antonio Garcia-Martinez are employed by the GSK group of companies. Desmond Curran and Maria del Rosario Cambronero hold shares in the GSK group of companies. All authors declare no other financial and non-financial relationships.

Compliance with Ethics Guidelines. This study was conducted in accordance with the ethical principles originating in the Declaration of Helsinki, the principles of Good Clinical Practice, and all applicable regulatory requirements. Written informed consent was obtained from each enrolled participant prior to any study data collection. The study protocol, the informed consent form, and other information that required pre-approval were reviewed and approved by the investigational center independent ethics committee (IEC) or institutional review board (IRB) for each of the participating primary care networks. These committees were the following: Comité Ético de Investigación Clínica Corporativo de Atención Primaria de la Comunitat Valenciana, Comité Ético de Investigación Clínica de la FUNDACIÓ UNIO CATALANA HOSPITALS, and Comité Ético de Investigación Clínica del Hospital Universitario Ramón y Cajal. The study protocol was posted on GSK's Clinical Study Register www.gskclinicalstudyregister.com GSK Study ID 114617) and on the US National Library of Medicine NIH website www.clinicaltrials.gov (NCT01521286).

Data Availability. GSK makes available the anonymized individual participant data and associated documents from interventional clinical studies which evaluate medicines upon approval of proposals submitted to www. clinicalstudydatarequest.com. To access data for other types of GSK sponsored research, for study documents without patient-level data and for clinical studies not listed, please submit an enquiry via www.clinicalstudydatarequest.com. The datasets generated during and/or analyzed during the current study are available from the corresponding author on reasonable request.

Open Access. This article is licensed under a Creative Commons Attribution-NonCommercial 4.0 International License, which permits any non-commercial use, sharing, adaptation, distribution and reproduction in any medium or format, as long as you give appropriate credit to the original author(s) and the source, provide a link to the Creative Commons licence, and indicate if changes were made. The images or other third party material in this article are included in the article's Creative Commons licence, unless indicated otherwise in a credit line to the material. If material is not included in the article's Creative Commons licence and your intended use is not permitted by statutory regulation or exceeds the permitted use, you will need to obtain permission directly from the copyright holder. To view a copy of this licence, visit http://creativecommons.org/licenses/by$\mathrm{nc} / 4.0 /$.

\section{REFERENCES}

1. Cohen JI. Clinical practice: herpes zoster. N Engl J Med. 2013;369:255-63.

2. Kawai K, Rampakakis E, Tsai TF, et al. Predictors of postherpetic neuralgia in patients with herpes zoster: a pooled analysis of prospective cohort studies from North and Latin America and Asia. Int J Infect Dis. 2015;34:126-31.

3. Katz J, Cooper EM, Walther RR, Sweeney EW, Dworkin RH. Acute pain in herpes zoster and its impact on health-related quality of life. Clin Infect Dis. 2004;39:342-8.

4. Coplan PM, Schmader K, Nikas A, et al. Development of a measure of the burden of pain due to herpes zoster and postherpetic neuralgia for prevention trials: adaptation of the brief pain inventory. J Pain. 2004;5:344-56.

5. Oster G, Harding G, Dukes E, Edelsberg J, Cleary PD. Pain, medication use, and health-related quality of life in older persons with postherpetic neuralgia: results from a population-based survey. J Pain. 2005;6:356-63. 
6. Schmader KE, Sloane R, Pieper C, et al. The impact of acute herpes zoster pain and discomfort on functional status and quality of life in older adults. Clin J Pain. 2007;23:490-6.

7. Johnson RW, Bouhassira D, Kassianos G, Leplege A, Schmader KE, Weinke T. The impact of herpes zoster and post-herpetic neuralgia on quality-oflife. BMC Med. 2010;8:37.

8. Gater A, Abetz-Webb L, Carroll S, Mannan A, Serpell M, Johnson R. Burden of herpes zoster in the UK: findings from the zoster quality of life (ZQOL) study. BMC Infect Dis. 2014;14:402.

9. Drolet $\mathrm{M}$, Brisson $\mathrm{M}$, Schmader KE, et al. The impact of herpes zoster and postherpetic neuralgia on health-related quality of life: a prospective study. CMAJ. 2010;182:1731-6.

10. Gater A, Uhart M, McCool R, Preaud E. The humanistic, economic and societal burden of herpes zoster in Europe: a critical review. BMC Public Health. 2015;15:193.

11. Varghese L, Standaert B, Olivieri A, Curran D. The temporal impact of aging on the burden of herpes zoster. BMC Geriatr. 2017;17:30.

12. Pinchinat S, Cebrián-Cuenca AM, Bricout H, Johnson RW. Similar herpes zoster incidence across Europe: results from a systematic literature review. BMC Infect Dis. 2013;13:170.

13. Salvetti A, Ferrari V, Garofalo R, et al. Incidence of herpes zoster and postherpetic neuralgia in Italian adults aged $>/=50$ years: a prospective study. Prev Med Rep. 2019;14:100882.

14. Schmidt-Ott R, Schutter U, Simon J, et al. Incidence and costs of herpes zoster and postherpetic neuralgia in German adults aged $>/=50$ years: a prospective study. J Infect. 2018;76:475-82.

15. Yanni EA, Ferreira G, Guennec M, et al. Burden of herpes zoster in 16 selected immunocompromised populations in England: a cohort study in the Clinical Practice Research Datalink 2000-2012. BMJ Open. 2018;8:e020528.

16. Muñoz-Quiles C, Lopez-Lacort M, Diez-Domingo J, Orrico-Sanchez A. Herpes zoster risk and burden of disease in immunocompromised populations: a population-based study using health system integrated databases, 2009-2014. BMC Infect Dis. 2020;20:905.

17. Munoz-Quiles C, Lopez-Lacort M, Diez-Domingo J. Risk and impact of herpes zoster among COPD patients: a population-based study, 2009-2014. BMC Infect Dis. 2018;18:203.
18. Morant-Talamante N, Diez-Domingo J, MartinezUbeda S, Puig-Barbera J, Aleman-Sanchez S, PerezBreva L. Herpes zoster surveillance using electronic databases in the Valencian Community (Spain). BMC Infect Dis. 2013;13:463.

19. Munoz-Quiles C, Lopez-Lacort M, Orrico-Sanchez A, Diez-Domingo J. Impact of postherpetic neuralgia: a six year population-based analysis on people aged 50 years or older. J Infect. 2018;77:131-6.

20. Salleras L, Salleras M, Salvador P, et al. Herpes zoster and postherpetic neuralgia in Catalonia (Spain). Hum Vaccin Immunother. 2015;11:178-84.

21. Cebrián-Cuenca AM, Diez-Domingo J, San-MartinRodriguez M, Puig-Barbera J, Navarro-Perez J, Herpes Zoster Research Group of the Valencian Community. Epidemiology and cost of herpes zoster and postherpetic neuralgia among patients treated in primary care centres in the Valencian community of Spain. BMC Infect Dis. 2011;11:302.

22. Sicras-Mainar A, Navarro-Artieda R, Ibanez-Nolla J, Perez-Ronco J. Incidence, resource use and costs associated with postherpetic neuralgia: a population-based retrospective study. Rev Neurol. 2012;55:449-61.

23. Lukas K, Edte A, Bertrand I. The impact of herpes zoster and post-herpetic neuralgia on quality of life: patient-reported outcomes in six European countries. Z Gesundh Wiss. 2012;20:441-51.

24. Curran D, Oostvogels L, Heineman T, et al. Quality of life impact of a recombinant zoster vaccine in adults aged 50 years and older. J Gerontol A Biol Sci Med Sci. 2019;74(8): 1231-8.

25. Curran D, Schmidt-Ott R, Schutter U, Simon J, Anastassopoulou A, Matthews S. Impact of herpes zoster and postherpetic neuralgia on the quality of life of Germans aged 50 or above. BMC Infect Dis. 2018;18:496.

26. Matthews S, De Maria A, Passamonti M, et al. The economic burden and impact on quality of life of herpes zoster and postherpetic neuralgia in individuals aged 50 years or older in Italy. Open Forum Infect Dis. 2019;6:ofz007.

27. Mizukami A, Sato K, Adachi K, et al. Impact of herpes zoster and post-herpetic neuralgia on health-related quality of life in Japanese adults aged 60 years or older: results from a prospective observational cohort study. Clin Drug Investig. 2018;38: 29-37.

28. Rabin R, de Charro F. EQ-5D: a measure of health status from the EuroQol Group. Ann Med. 2001;33: 337-43. 
29. EuroQoL. https://euroqol.org/. Accessed 26 Oct 2020.

30. Cunningham AL, Lal H, Kovac M, et al. Efficacy of the herpes zoster subunit vaccine in adults 70 years of age or older. N Engl J Med. 2016;375:1019-32.

31. McPhail S, Lane P, Russell T, et al. Telephone reliability of the Frenchay Activity Index and EQ-5D amongst older adults. Health Qual Life Outcomes. 2009;7:48.

32. Chatterji R, Naylor JM, Harris IA, et al. An equivalence study: are patient-completed and telephone interview equivalent modes of administration for the EuroQol survey? Health Qual Life Outcomes. 2017;15:18.

33. Badia X, Roset M, Herdman M, Kind P. A comparison of United Kingdom and Spanish general population time trade-off values for EQ-5D health states. Med Decis Making. 2001;21:7-16.

34. Consejería de Sanidad y Asuntos Sociales, 17/11/ 2014 Official Tariffs of Healthcare Services. http:// noticias.juridicas.com/base_datos/CCAA/539877orden-sanidad-y-asuntos-sociales-17-nov-2014-cacastilla-la-mancha-precios.html. Accessed 14 Mar 2019.
35. BotPLUS web database. Official General Council of the College of Pharmacists of Spain. Madrid. https://botplusweb.portalfarma.com/. Accessed 14 Mar 2019.

36. Gil A, Gil R, Alvaro A, San Martin M, Gonzalez A. Burden of herpes zoster requiring hospitalization in Spain during a seven-year period (1998-2004). BMC Infect Dis. 2009;9:55.

37. Garcia I, Portugal C, Chu LH, Kawatkar AA. Response rates of three modes of survey administration and survey preferences of rheumatoid arthritis patients. Arthritis Care Res (Hoboken). 2014;66:364-70.

38. Song H, Lee J, Lee M, et al. Burden of illness, quality of life, and healthcare utilization among patients with herpes zoster in South Korea: a prospective clinical-epidemiological study. Int $\mathrm{J}$ Infect Dis. 2014;20:23-30.

39. Serpell M, Gater A, Carroll S, Abetz-Webb L, Mannan A, Johnson R. Burden of post-herpetic neuralgia in a sample of UK residents aged 50 years or older: findings from the Zoster Quality of Life (ZQOL) study. Health Qual Life Outcomes. 2014;12: 92. 